\section{From Conexa to Docpass: The Competitive Environment of Telemedicine Platforms}

\author{
Da Conexa ao Docpass: O Ambiente Competitivo das Plataformas de \\ Telemedicina
}

Discipline: Strategy and Innovation

Subject: Platforms

Industry: Health

Geography: Rio de Janeiro/Brazil
Catia Silva da Costa Moreira ${ }^{1}$ [] Flavia d'Albergaria Freitas ${ }^{2}$ 우 Carolina Brandão 3 (을 Cláudia Affonso Silva Araujo ${ }^{2,4}$

\title{
INTRODUCTION
}

It was already late in the afternoon on a Thursday in June 2020 when Fernando signed off from a video conference meeting with his partner Guilherme Weigert. Conexa Saúde was a telemedicine platform focused on the business-to-business (B2B) segment, providing services for health institutions and companies. During the coronavirus pandemic (COVID-19), Conexa took advantage of the change in legislation to launch its telemedicine platform named Docpass, a spin off from the company with a business-to-consumer (B2C) focus that connects certified physicians with end consumers.

Those months of social distancing due to COVID-19 were not being easy for Fernando Domingues, the founder and head of Conexa Saúde's sales division. It had been a month now of not leaving his home, so he was eager to get back to his hectic routine as a young entrepreneur. Fernando was proud to

1. Universidade Federal Fluminense, Faculdade de Administração e Ciências Contábeis, Departamento de Empreendedorismo, Niterói, RJ, Brazil.

2. Universidade Federal do Rio de Janeiro, Instituto COPPEAD de Administração, Rio de Janeiro, RJ, Brazil. 3. Pontifícia Universidade Católica do Rio de Janeiro, Rio de Janeiro, RJ, Brazil.

4. Fundação Getulio Vargas, Escola de Administração de Empresas de São Paulo, São Paulo, SP, Brazil.

Cite as: Moreira, C. S. da C., Freitas, F. D., Brandão, C., \& Araujo, C. A. S. (2021). From Conexa to Docpass: The competitive environment of telemedicine platforms. Revista de Administração Contemporânea, 25(spe), e200238. https://doi.org/10.1590/1982-7849rac2021200238.en

\# of invited reviewers until the decision: have founded "the largest independent telemedicine platform in Latin America" together with two partners.

Until the beginning of 2020, Conexa only offered $\mathrm{B} 2 \mathrm{~B}$ telemedicine solutions, but it always wanted to get into the B2C segment and, in 2019, it even created a platform by which a patient could access doctors, but the initiative stagnated due to legislation. However, in April 2020, due to the coronavirus, a law was passed that allowed telemedicine to be practiced while the pandemic situation was in force, so the demand for tele-health care services increased significantly, representing a strong indication that there was potential in the B2C segment. In view of this opportunity, the partners created Docpass. In just three months, the number of patients and physicians registered on the platform grew dramatically from 100,000 to 4 million patients and from 3,000 to more than 10,000 physicians.
JEL Code: A20, 114, D12 Editor-in-chief: Wesley Mendes-da-Silva (Fundação Getulio Vargas, EAESP, Brazil) (c) Associate Editor: Paula C. P. de S. Chimenti (Universidade Federal do Rio de Janeiro, COPPEAD, Brazil) (C) Guest Editor: Leonardo Marques (Universidade Federal do Rio de Janeiro, COPPEAD, Brazil) Reviewers: Lourival Chaves Júnior (Unidade de Ensino Superior do Sul do Maranhão, Brazill) Adrian Kemmer Cernev (Fundação Getulio Vargas, EAESP, Brazil) (c) Peer Review Report: The Peer Review Report is available at this external URL. Received: July 15, 2020 Last version received: December 01, 2020 Accepted: December 07, 2020

\begin{tabular}{|c|c|c|c|c|c|c|c|c|c|}
\hline & 1 & 2 & 3 & 4 & 5 & 6 & 7 & 8 & 9 \\
\hline $1^{\text {st }}$ round & $\stackrel{0}{2}$ & 9 & & & & & & & \\
\hline $2^{\text {nd }}$ round & $\stackrel{0}{2}$ & & & & & & & & \\
\hline $3^{\text {rd }}$ round & $\stackrel{0}{=}$ & & & & & & & & \\
\hline
\end{tabular}


The partners were, however, aware of the challenges that the new platform posed. During the video call, Fernando and Guilherme discussed some issues that concerned them such as how to continue growing considering the increase in competition. More importantly still was the question of how to create value and retain patient and physician loyalty to Docpass considering the broad offer of telemedicine platforms. As there were more doubts than certainties at that time, they decided to make a detailed assessment of the entire situation and meet again in a week.

\section{CONEXA'S HISTORY}

Conexa was founded in early 2017 with the concept of a standard health clinic site located in the Copacabana district of Rio de Janeiro, where the company received patients in person for primary care, but with the help of telemedicine could evolve into appointments with specialists. The general practitioners exercised their activities in person and could contact medical specialists via telemedicine to assist them in dealing with patient cases. According to Guilherme, "It was a brick-andmortar general clinic that offered a telemedicine option to establish a patient journey with a focus on his or her general practitioner."

However, this model went against the culture of patients wanting to look for specialist doctors, along with the difficulty of managing fixed costs. So, in the beginning of 2018, the partners decided to implement changes and turn to what became the heart of the business - telemedicine services exclusively. The actual physical site of the general clinic for providing in-person care was closed and they developed their own platform that made it possible to carry out tele-appointments by connecting physicians and patients. But the previous clinic experience had taught them a lot. Patients did perceive great value when they could solve their entire problem at a single point of contact. "The patients would leave with a single prescription and with only one exam request. This, in the patient's mind, was an incredible perception. "Wow! I've never seen two doctors talking about my case. I've never received only one prescription." That was the key point." (Guilherme).

This lesson learned inspired the telemedicine solution. Because the platform had the entire patient's history, during the appointment the doctor had access to the previous medical records and could change, add, or maintain a single prescription.

In order to grow, Conexa counted on the investment of its partners and also from other individuals and funds. Later on, the company raised funds with a board of physicians represented by renowned professionals willing to invest in the platform and support the product's development. During these years of operations, Conexa managed to catch the attention of large Brazilian groups that became its partners and clients (Annex 1). Up until March 2020, there were two types of B2B offers: (a) teleappointment services where the client companies offered this service as a benefit to their employees; and (b) a subscription that allowed health institutions to use the telemedicine platform (white label) to offer their services while using their own networks of physicians. This use of subscription software is called software as a service (SaaS).

In the tele-appointment mode, large companies would make Conexa's telemedicine services available to their employees. These services could include, for example, occupational health such as doing health exams when hiring and laying off, or for primary care serving as screening in cases of urgencies occurring in the work environment. The tele-appointments were done by physicians certified in the Conexa network and could take place both at a marked time or in an emergency situation. The pricing was per employee. The company paid a low fixed amount per employee to have direct service, while Conexa controlled the company's entire primary health care by telemedicine for this amount contracted. Despite the fixed amount, Conexa wanted its service to be widely used by the contracting company so that it could realize the investment's value. "When we go into a company, we run a giant marketing campaign, an activation campaign. We begin to do mailing with the employees, contacting everyone, and letting them know that they have telemedicine. Why do we do that? Because if we sell telemedicine to the company and they don't use it, they are going to pay for three months and then cancel. So, it's much better to be proactive than reactive." (Fernando).

The business model also considered the attraction and retention of the network of physicians registered. They worked on an on-call scheme, so the remuneration was equivalent to that of an on-call rate in a private hospital. At the beginning of 2020, Conexa had about 3,000 registered physicians who provided services for 100,000 patients. There were also situations where the business model involved a health insurance company: "We have a large retail company whose health insurance company of the employees recommends using Conexa. The retailer pays Conexa. The Health Insurance Plan is only a bridge, a channel, but with no direct relation with Conexa." (Fernando).

In the SaaS modality, Conexa offered only white label software and technical support, allowing the client company to enter its visual identity and provide tele-appointment using its own network of accredited physicians. 


\section{THE REGULATION OF TELEMEDICINE IN BRAZIL AND THE IMPACTS OF COVID-19}

Telemedicine has been a part of Brazilian reality for some time, but it remained the subject of debates and controversies. In 2002, the Federal Council of Medicine (Conselho Federal de Medicina - CFM, in Portuguese) passed Resolution CFM No. 1,643/2002 ${ }^{1}$ to define and discipline the services provided through telemedicine, but due to technological evolution and transformations in the practices of medicine, many concepts and forms of action became deregulated. In order to fill this gap and make the legal environment clearer, in early February 2019, CFM announced the publication of Resolution CFM No. 2,227/2018 ${ }^{2}$, which also aimed to detail and define activities related to telemedicine. The issue, however, was far from being resolved. As soon as the CFM published this resolution, part of the medical community and trade associations stated their resistance to the CFM, and because of this the resolution was revoked by the Council on February 22, 20193.

But what no one expected is that a year later the scenario would change dramatically: COVID-19 arrived in Brazil in February 2020, demanding a quick response to telemedicine regulation. Thus, on April 15, 2020, Law No. 13,989 was sanctioned authorizing the practice of telemedicine during the pandemic ${ }^{4}$. Through distance health care, patients were able to connect with doctors safely, providing several benefits such as monitoring chronic patients, providing primary care, answering doubts, and lowering the number of people arriving at the emergency unit since they represented a contamination risk for the patient and an overload on the health system.

The regulation thus gave an opportunity to companies such as Conexa to join the context of telehealth. However, considering that the law was valid only during the COVID-19 pandemic, there was no guarantee of telemedicine's legality in the future.

\section{DOCPASS, A B2C OFFER}

As soon as Law No. 13,989 passed, Conexa's partners decided to take advantage of the opportunity. With more investment, it would be possible to give access to $75 \%$ of the population that did not have health insurance and who had difficulty in receiving good medical care. "The approval of direct telemedicine for the patient opened the market for 150 million users who do not have health insurance today. We also want to provide services in the sphere of those who do not have health insurance and need medical access." (Fernando).
However, that was not the first time that they had thought of entering the B2C model. In 2019, with the first attempt to approve telemedicine, investments were made to create the new solution, but the legislation was repealed and the partners took a step backwards and decided to prepare better and to further develop the product. So, with the regulations approved in 2020, the platform was ready to launch Docpass. "We started to see a very large utilization curve on the platform. Within a few days, we went from 40-50 appointments to 2,000 appointments a day. With that growth, we said to ourselves: Now is the time. The platform is ready. We are managing, the system did not crash, everything is okay, so now is the time to go to the B2C market." (Guilherme).

Docpass was created to ensure the focus of the entire team on the B2C target audience. "It doesn't work having only one team looking after both B2B and B2C. They are different markets - everything is different." (Fernando).

There was also a concern about not creating noise with the B2B customers. "We had a lot of discussion about this because it made sense [to keep Conexa brand] from the point of view of synergy, but there were the risks of conflicts. We wanted to protect ourselves from this potential problem. We did not confuse the user and we didn't attract the B2B customer to our B2C brand." (Guilherme).

The two companies, Conexa and Docpass, took advantage of some synergies such as the platform's development, legal department, and back office, but the teams were different for more specific areas such as communication, marketing, customer acquisition, and sales.

The partners knew that they would need to develop a completely new communication approach to attract patients and that they would need to expand the number of doctors on call. However, COVID-19 had not only made it possible to change legislation, but it had also broken down a cultural barrier about using telemedicine. For patients, telemedicine offered a safer path, reducing the chances of contagion, while for the physicians, remote care brought safety and represented a way to maintain their professional activities and care for patients.

One big challenge was to prepare the new platform for the means of payment, which did not exist on the $\mathrm{B} 2 \mathrm{~B}$ platform. It took three weeks of investments in technology to launch a credit card payment feature. Another challenge was to define the value proposition for the patient and for what the target would be. There was no time to do market survey work. The solution was to launch the platform and start testing it. Tests were conducted with the $\mathrm{B}+$ public and then with C. All was done digitally with a dedicated growth team that performed an $\mathrm{A} / \mathrm{B}$ test, a campaign test, and a sensitivity test. Interviews were conducted with patients who 
had used the platform in order to improve it, as well as with those who logged in but did not set up an appointment.

There was also the challenge of bringing new doctors on board, given that the potential for providing care would grow greatly with the new company. The physicians who already provided services for the B2B platform were plugged into the new platform. Campaigns were also carried out on medical societies and health insurance companies to attract newcomers. Thus, the new platform was quickly populated with doctors. But it was also necessary to attract patients: "We are very aggressive with digital marketing on the B2C channel because it's direct marketing with the patient, so I'm talking about Google and a lot of content. We set up a blog to talk about telemedicine, we do lives on Instagram... so it's more specific marketing." (Fernando).

Docpass used virtual channels to communicate with the public and also established partnerships with other companies. The main partner was the drugstore chain Droga Raia that set up a website with content about COVID-19 and called five telemedicine companies to participate, one of them being Conexa/Docpass. So, two strategies were used: one for internal growth, very focused on digital, considering customer acquisition cost, lifetime value, and well-targeted campaigns; and the second one that looked at segmented massification channels such as drugstores, e-commerce platforms, delivery channels, and banks.

For patients and physicians to join, they simply needed to download the app and enter their information. Once the patient does this, he or she was already active on the platform. As for the physicians, however, they underwent a registration validation process that typically took five days. Their medical license, résumé, diploma, specialization, and experience as a doctor were evaluated, similarly to what takes place for traditional on-call medical services. Then there was an interview process and a short training. Only then would the professional be approved to work. On the platform, the patient could choose one of the physicians registered, evaluating his/her résumé, medical license, specialization, and average score received by the professional from previous appointments. In addition to the tele-appointment, which could take place via video conference, chat, or a voice call, the platform offered electronic prescriptions of medications and exams.

A Docpass tele-appointment cost $\mathrm{R} \$ 100$. Of this amount, $20 \%$ went to the platform and $80 \%$ to the doctor - a share model similar to other platforms that have already been consolidated on the market. In the first months of the B2C platform, in order to expand its patient network more quickly, Docpass offered a discount of R $\$ 50.00$ without affecting the physicians' remuneration. As the network of doctors accredited by Docpass is the same as the B2B offer, entering the $\mathrm{B} 2 \mathrm{C}$ market ended up helping optimize the capacity of providing on-call appointments. The physicians who typically joined the platform were young doctors who had recently finished medical school. The most sought out medical specialties at Docpass were general practitioners, dermatologists, and psychiatrists. Specialties depending on a more thorough clinical examination were not offered.

The platform allowed the patient's medical records to be stored, with patients having access to visualize them. Docpass did not monetize medical records. As Fernando saw it, this medical record would represent a cost of change for the patient: "Once a patient had a detailed record on a platform, he would hesitate to change to another platform." But the partners knew that the strongest exit barrier would be the experience and the relationship the patients would build. For the patient to choose Docpass, it would be necessary to have an easy, intuitive experience and to have quality physicians. "Focus on the quality of service. A service without faults. A 24-hour service in which the wait time would be the shortest possible. These are things that the product would have in its favor. And then there is the brand. Once we strengthen this brand and position it as a brand that is innovating, that is thinking of a very good service for that user, it will start to build loyalty." (Guilherme).

The value proposition was being improved over time. "We took all the value propositions that would really be addressed by this audience and we started to offer them. We noticed that they [the patients] wanted specialists, so we brought specialist doctors. Then it was mental health, so we incorporated mental health. And now we are running engagement tests using post-notification campaigns to see if they return to the platform. These are ways that we have today to engage the user and partnerships. Discount at drug stores, discount on medical exams. Start bringing added value into our product." (Guilherme).

Furthermore, the company focused on three pillars in order to ensure the service quality: curatorship, Net Promoter Score (NPS), and protocols. Curatorship through résumé analysis was responsible for ensuring that the platform had good doctors. The NPS was the instrument used by patients to evaluate the platform and the physician after the appointment, generating an average score that was linked to the doctor's profile. There was also room for suggestions for improvement. When an appointment received a bad score, contact was tried to be made to talk to the user to understand the reason. Each case was categorized. When it was a system or physician failure, there was a more specific intervention than when it was the patient's connection problem, for example. A barrier faced by class $C$ patients was poor quality internet access, damaging the tele-appointment experience. The third pillar was the protocols offered by Docpass to assist doctors in decision-making and to ensure the quality of the appointments. 
The partners understood that it was necessary to accelerate growth even further. One idea was to join platforms from other sectors such as Rappi, Americanas, and Magalu so that they could offer telemedicine on their portfolio.

\section{THE COMPETITIVE ENVIRONMENT}

A new competitive environment was formed with the approval of telemedicine and Conexa became part of a competitive, complex environment marked by the presence of organizations that have different characteristics. Some of them were already active in the telemedicine sector before COVID-19, such as the global competitor Teladoc, while others were driven by the crisis to position themselves more strongly in the market and to enter the telemedicine sector, such as Dr. Consulta. Some of the main competitors are highlighted below:

Teladoc Health: a multinational company considered a global leader in virtual health care created in 2002 in the United States. It is present in several countries such as China, Australia, Canada, France, the United Kingdom, Spain, Portugal, and Hungary. With the pandemic, demand for their appointments doubled, reaching more than 20,000 appointments per $\mathrm{day}^{5}$, and presented a higher result than expected in its revenues for the first quarter of 2020. The company arrived in Brazil in early 2020 and launched the Teladoc App for carrying out telemedicine directly with patients.

Docway: founded in 2015 in Curitiba, Docway is a company that has been growing for some time in the sector with innovations in health care. It initially was a platform for connecting physicians and patients for personalized home care and, in 2018, the company began to offer telemedicine activities as a complement to its primary service. Its business model allows patients to choose their doctors according to the specialty desired and then they reach an agreement as to the place for the appointment to take place - either at their home or at another location. It is especially aimed at low complexity cases and there is no emergency care. The company offers services both as B2B, with relationships with insurance companies, and as B2C. The Docway App covers more than 250 cities in Brazil. In order to deal with the pandemic, the company inserted its tele-orientation services together with the health insurance benefits to avoid going to the emergency room and being exposed to the new virus.

Dr. Consulta: considered to be the largest Brazilian healthtech company and winner of the international social entrepreneurship award, it is a physical network of medical centers that provide general clinic and medical specialties services along with dentists, medical exams, and small surgeries. It was created in 2011 in the city of São Paulo in the neighborhood of Heliópolis. By 2020, it was present in the states of São Paulo, Rio de Janeiro, and Minas Gerais. Its positioning is to have a social impact and increase access to health among the population, especially for people without health insurance. COVID-19 pushed the company toward entering telemedicine, and it launched Dr. Consulta Online, its telemedicine service that uses the physical network's own physicians to provide scheduled online tele-appointments at cheaper prices than in-person appointments and varying according to the desired medical specialty.

Meanwhile, large companies in the Brazilian health sector such as insurance companies, hospitals, and diagnostic medicine companies have taken steps toward including distance health care in their offer. Hospital Israelita Albert Einstein was already using telemedicine to conduct appointments and tele-consultation/liaison among physicians even before the pandemic. Fleury Group's diagnostic medicine, with social distancing, launched its Cuidar Digital platform for tele-appointments that has electronic medical records and access to exams with the group's brands. Another diagnostics company, Dasa, created a COVID-19 awareness platform and opened medical care fronts using telemedicine.

As for the competition, Fernando reinforced the pioneering spirit of Conexa/Docpass in telemedicine in Brazil as a great differential. "We have been investing in the platform for more time, in the patient's experience, in the doctor's experience. We have a better product today because we have been doing this longer. We have an NPS of $87 \%$. We can explain this very high NPS because we have already made mistakes, made the necessary corrections, and today we have a lot of experience because we were the first independent telemedicine platform in Brazil." (Fernando).

Guilherme wanted to point out that competition would increase greatly: "I don't think it's a space for a single player because the market is very large, and it will be very segmented. There are going to be platforms that will be super good in mental health, while others put a focus on diabetes. We want to be more comprehensive through partnerships or acquisitions in order to actually have the majority of this market." (Guilherme).

\section{WHAT IS THE POST COVID-19 SCENARIO?}

Fernando had prepared for the next video conference with Guilherme and he began talking about his belief in the potential of telemedicine. In just a few months, Conexa had left the models mediated by companies and was providing direct services to the patient, but there was still a lot ahead. "We think that the market will continue 
to expand in post-COVID because telemedicine here in Brazil has not even reached $1 \%$ of the market compared with the United States, which is already a much more advanced market. So at least in the next five years we are going to see everyone's exponential growth - of all the partners." (Fernando).

However, there was something that worried Fernando a lot. What would happen to the regulation once the pandemic was over? "A challenge for us today is the legal aspect. We hope that telemedicine will continue to be approved, but there is that legal risk. At any time, CFM can once again put up barriers on telemedicine," Fernando pondered.

Guilherme believed that the future would come from science. "Science is a very important point. We have been very concerned about science in telemedicine by bringing data, structuring data for us to prove that telemedicine is in fact positive and that it is safe. Doctors believe strongly in evidence-based medicine. So, if we don't bring this to the table, we are always going to be struggling with "what I think" and not with what is. So, this is a big concern and we have talked with our competitors, with our partners, for science to become a part of this in a more robust way." (Guilherme).

Even with these concerns, they agreed that it was not time to reduce Conexa's momentum if they wanted to continue to position themselves as "the largest independent telemedicine platform in Latin America." Like every platform, they needed to expand their user base. How would they do that? What would happen with the issue of competition and partnerships after the pandemic? How to create more value for the platform? The brainstorming was just beginning.

\section{NOTES}

1. Resolução CFM n. 1.643/2020. (2020). Define e disciplina a prestação de serviços através da Telemedicina. Retrieved from https://sistemas.cfm.org.br/normas/visualizar/ resolucoes/BR/2002/1643

2. Resolução CFM n. 2.227/2018. Revogada. (2019). Define e disciplina a telemedicina como forma de prestação de serviços médicos mediados por tecnologias. Retrieved from https://sistemas.cfm.org.br/normas/visualizar/resolucoes/ $\mathrm{BR} / 2018 / 2227$

3. Conselho Federal de Medicina. (2019). Retrieved from https://portal.cfm.org.br/index.php?option $=$ com content

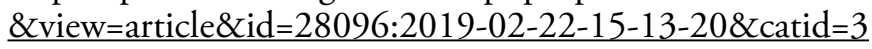

4. Lei n. 13.989 de 15 de abril de 2020. (2020). Dispóe sobre o uso da telemedicina durante a crise causada pelo coronavírus (SARS-CoV-2). Retrieved from http://www. in.gov.br/en/web/dou/-/lei-n-13.989-de-15-de-abrilde-2020-252726328

5. Krouse, S. (2020). Teladoc's remote doctor visits surge in Coronavirus crisis. The Wall Street Journal. Retrieved from https://www.wsj.com/articles/teladocs-remote-doctorvisits-surge-in-coronavirus-crisis-11586894400? $\mathrm{mod}=$ searc $\underline{\text { hresults\&page }=1 \& \text { pos }=3}$ 


\section{ANNEX 1}

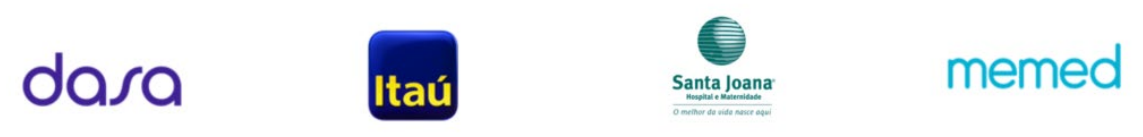

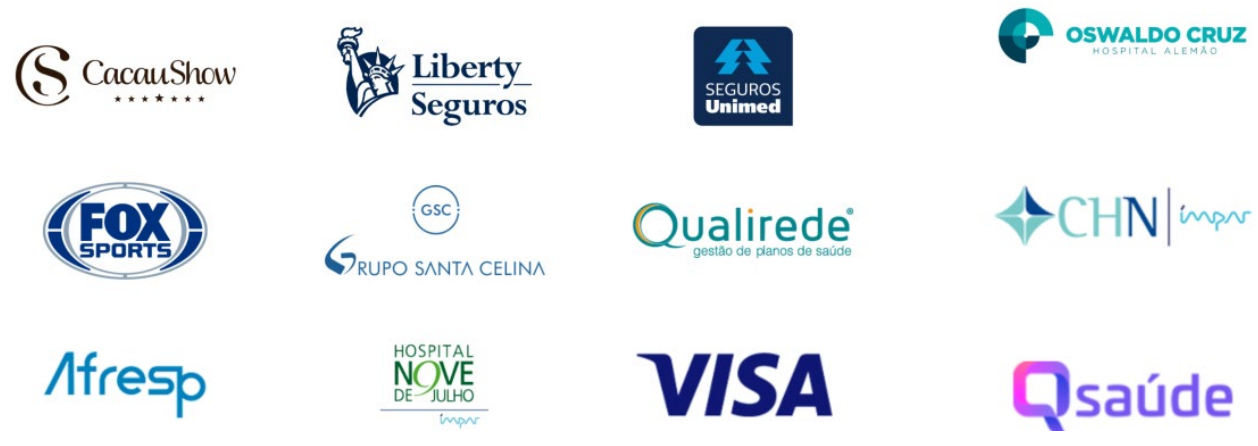

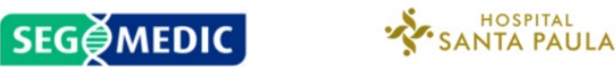

Figure A1. Conexa's clients. 


\section{ABSTRACT}

The case reports the trajectory of a telemedicine platform in Brazil. Conexa, a company that already operated with a telemedicine B2B model, took advantage of the regulatory change during the coronavirus pandemic (COVID-19) and launched Docpass, a B2C platform. The pandemic not only brought about a change in legislation, but also provided a context that reduced cultural barriers to the adoption of such a service for both doctors and patients. The case is recommended for Strategy and Innovation disciplines, more specifically in sessions dedicated to business models based on platforms, when the following learning objectives are worked on: (a) diagnosis of COVID-19 effects in a telemedicine business by comparing before, during, and after the pandemic; (b) understanding the network effects present on the platforms and their reflections in terms of value; (c) understanding the competitive dynamics in a platform ecosystem.

Keywords: platform; network effects; coopetition; telemedicine.

\section{Educational objectives}

This teaching case has been developed to be used in undergraduate, extension, or graduate courses in Business Administration and can be employed in disciplines related to Strategy and Innovation, more specifically in sessions dedicated to platform-based business models. It can also be used in Health Services Management courses during a session on innovation. At the end of the case discussion, students are expected to increase their learning in the following areas: (a) diagnosis of COVID-19 effects on a telemedicine business by comparing before, during, and after the pandemic; (b) understanding the network effects present on the platforms and their reflections in terms of value; (c) understanding the competitive dynamics on a platform ecosystem.

While building these teaching notes, we opted to put a focus on the concepts of network effects and coopetition. However, the case allows other angles of analysis and discussion paths, which we record here with the respective literature indication so that the teacher can make evaluations according to his/her preferences: management of digital platforms (Tiwana, 2013); two-sided and/or multi-sided market (Hagiu, 2014); and imprisonment and cost to change (Shapiro \& Varian, 2003).

\section{RESUMO}

O caso narra a trajetória de uma plataforma de telemedicina no Brasil. A Conexa, uma empresa que já operava com modelo B2B com telemedicina, aproveitou a mudança de regulamentação durante a pandemia do coronavírus (COVID-19) e lançou a Docpass, uma plataforma B2C. A pandemia não trouxe somente a mudança na legislação, como também propiciou um contexto que reduziu as barreiras culturais para a adoção de tal serviço tanto para médicos quanto para pacientes. $\mathrm{O}$ caso é recomendado para disciplinas de Estratégia e Inovação, mais especificamente em sessões dedicadas aos modelos de negócios baseados em plataformas, quando forem trabalhados os seguintes objetivos de aprendizagem: (a) diagnóstico sobre desdobramentos do COVID-19 em um negócio de telemedicina comparando-se o antes, o durante e o depois; (b) compreensão dos efeitos de rede presentes nas plataformas e seus reflexos em termos de valor; (c) compreensão da dinâmica competitiva em um ecossistema de plataforma.

Palavras-chave: plataforma; efeitos de rede; coopetição; telemedicina.

\section{Characters and sources of information}

The case is presented from the point of view of two people, Fernando Domingues and Guilherme Weigert, partners at Conexa, a Brazilian telemedicine platform. Indepth semi-structured interviews were conducted with both partners that lasted one hour each. Secondary sources such as federal laws, Federal Council of Medicine regulations, websites, and reports were also used.

\section{Teaching plan}

The case may be used with or without prior reading recommendation, depending on the teacher's preference. If the teacher chooses not to recommend prior reading, he or she can guide the students to research the concepts about which they are not familiar during the reading of the case. In this context, it is recommended that during the discussion the teacher go deeper into concepts such as B2B, B2C, SaaS, and others as they emerge. On the other hand, if the teacher prefers to recommend previous readings for students to become familiar with the concepts related to the platformbased business model, suggested reading could be chapters 2 and 10 of the book Platform Revolution, by Parker, Van Alstyne and Choudary (2018). 
The case was developed assuming prior individual extra-class preparation by the students.

We estimate the total time for discussing the case to be 120 minutes, so the discussion time will have to be adjusted depending on typical class duration, but the teacher may choose a longer discussion if there is more time available. The first 20 minutes should be dedicated to discussion in small groups. The discussion with the entire class can range from 80 to 100 minutes depending on the typical distribution of class hours. The opening of the debate with the entire class using Slide 1 of the table proposed (see Appendix) should take 10-15 minutes. Analysis of case questions on Slides 1 to 5 of the table proposed (see Appendix) should take 60-75 minutes. Wrapping up the debate with the entire class will take up the remaining 10 minutes.

\section{Questions for discussion}

Below is a set of discussion questions that could be used to stimulate analyzing the case with the entire class:

1. How did Conexa view and take action during the telemedicine scenario in Brazil before the pandemic?

2. How did Conexa react to the telemedicine regulation that occurred during the pandemic?

3. What are the post-COVID-19 challenges in relation to the competitive environment of telemedicine in Brazil?

\section{Analysis of the case with the entire class}

\section{Opening the case for discussion with the entire class}

The opening of the discussion can be used to explore how the telemedicine scenario in Brazil was before COVID-19. To do this, the teacher could ask: "How can we characterize the telemedicine scenario in Brazil BEFORE the pandemic?" Student responses may raise some of the following aspects:

- The technology needed for telemedicine was already available (+).

- Cultural barrier - distrust in telemedicine (-).

- Educational barrier - lack of technological skills by users (-). But younger patients and physicians were already more familiar with the technology $(+)$.

- An attempt to regulate telemedicine in 2019 fails due to resistance and protests from medical associations $(-)$.
The teacher can list the topics raised by the students to start building a comparison chart to be filled in by the end of the discussion. See Slide 1 of the Class Discussion Plan (Appendix).

\section{Answers to questions for discussion with support from literature}

Question 1: How did Conexa view and take action during the telemedicine scenario in Brazil before the pandemic?

The objective of this question is to map the impacts of COVID-19 on the business model of a platform company taking into account the competitive scenario in which it was inserted. To do so, the teacher can make the following transition questions (TQ):

TQ 1.1: How was the Conexa platform operating before the pandemic?

With the information provided from the case, the students can describe the modalities of Conexa's B2B offer (SaaS and tele-appointment) showing the sides connected through the platform. This question provides the opportunity for the teacher to design the ecosystem involved with Conexa's platform based on the contributions from the students. See Slide 1 of the Class Discussion Plan (Appendix).

With the complete B2B design, the teacher can guide the discussion so that inductively students can reflect on the platform's concept.

Platforms are "a new business model that uses technology to connect people, organizations, and resources in an interactive ecosystem in which amazing amounts of value can be created and exchanged" (Parker, Van Alstyne, \& Choudary, 2018, p. 11). Platforms gain economic advantages from digital environments (McAfee \& Brynjolfsson, 2017) by enabling and facilitating connections and by creating value among users who begin to exchange goods, services, information, ideas, and other intangible and social values (Parker et al., 2018). If students are unfamiliar with the platform concept, the teacher can make comparisons with other platforms such as Uber, Airbnb, Amazon Marketplace, and Facebook.

TQ 1.2: When considering the SaaS offer, which sides is the platform connecting? How does it generate value for these sides?

In the SaaS offer, Conexa (C) provided the technological resources for health institutions (HI) such as health insurance companies, hospitals, and diagnostic companies in order to offer their patients $(\mathrm{P})$ telemedicine services from these companies' medical network (M). Conexa obtained profits from its software. Institutions 
complemented their portfolio of offers without having to shift from their focus on health services to develop the necessary software. On the other hand, companies' customers could opt for telemedicine and deal with their health problems more conveniently and quickly, often avoiding, for example, a worsening of their conditions or going to the emergency room and thus potentially reducing costs for the insurance company.

TQ 1.3: And now, considering the offer of B2B services, which sides is the platform connecting? How does it generate value for these sides?

When providing B2B services, Conexa was contracted by large firms (F) and connected a network of Conexa's accredited physicians $(\mathrm{M})$ to their employees $(\mathrm{P})$ offering tele-appointments and tele-health care services. In this model, Conexa charges a fee to the large firms (according to the number of employees) and manages the provision of services profitably. Companies could offer their employees tele-health care as a benefit, enabling greater convenience and increasing their satisfaction, while reducing absenteeism, avoiding higher costs, and improving their image.

TQ 1.4: Before the pandemic, how was Conexa's vision regarding $\mathrm{B} 2 \mathrm{C}$ telemedicine?

The case shows that before the pandemic Conexa's leadership had already built a vision to work with the B2C market, taking advantage of the entire learning curve experienced with B2B. So, the company identified the opportunity with $\mathrm{B} 2 \mathrm{C}$ even before the industry's regulation. Following this vision, they have already prepared the groundwork for B2C as soon as the main barrier, the legal one, was overcome. Leadership had a central role in the company's innovative capacity since, along with managing the B2B business to increase its efficiency, it was able to predict opportunities while strengthening and disseminating the vision in order to support innovation as well.

TQ 1.5: How does the arrival of the pandemic change the context of telemedicine?

The teacher can list the topics raised by the students to fill out the comparison chart that was started at the opening of the discussion. See columns 2 and 3 of the Class Discussion Plan (Appendix).

- Remote care offered advantages for dealing with an infectious disease $(+)$.

- With social distancing, patients with other diseases also gave value to remote care be-cause they did not want to expose themselves to risks (+).

- Health services presented demands above their capacity, making remote care also have value $(+)$.
- Physicians needed to create ways to care for their patients while also generating reve-nue. Many began to value virtual health care $(+)$.

- Telemedicine laws and regulations were passed during the pandemic $(+)$.

- Health insurance companies started to pay for telehealth care services $(+)$.

- Doctors and the general population, due to the pressure from the situation, needed to learn and have contact with meeting platforms, e-commerce, and other information and communication technologies, acquiring skills and demystifying their use $(+)$.

- Some medical specialties were able to benefit immediately from the regulation $(+)$, while others were still limited due to the characteristics of the physical exams needed (-).

- Companies quickly placed their telemedicine solutions on the market with varying de-grees of maturity, learning during the process $(+/-)$.

The aspects mentioned show that the pandemic scenario was favorable to accelerating the deployment of telemedicine in the country, breaking down legal, cultural, educational, and economic barriers and opening up new opportunities for creating value.

Question 2: How did Conexa react to the telemedicine regulation that occurred during the pandemic?

This question makes it possible to detail the $\mathrm{B} 2 \mathrm{C}$ offer and the new brand created, Docpass, in order to explore the network effects present on the platforms and their reflections in terms of value on platform business models.

A suggestion would be for the teacher to go back to the ecosystem design and fill it out with the contributions from the students.

The entry of Conexa into a new market may be a good context for exploring the concept of network effects and their development in relation to value creation. In the logic of the platform market, the user community can affect both positively and negatively the platform's ability to generate value. In this sense, "positive network effects are the main source of value creation and competitive advantage on a business platform" (Parker et al., 2018, p. 27).

TQ 2.1: How does the platform generate value for physicians and patients on $\mathrm{B} 2 \mathrm{C}$ ?

Students may bring up that patients could gain value by being able to be helped quickly by a wide network of good professionals with convenience and quality so that they can satisfactorily solve their demands and pay a fair price. 
Analyzing the side of the doctors, students may mention that professionals would gain value by attracting new patients, higher volume of appointments, higher total remuneration (often telemedicine represents a complementary source of income), as well as a facilitated work experience, convenient, and with a quality infrastructure (Figure 1).
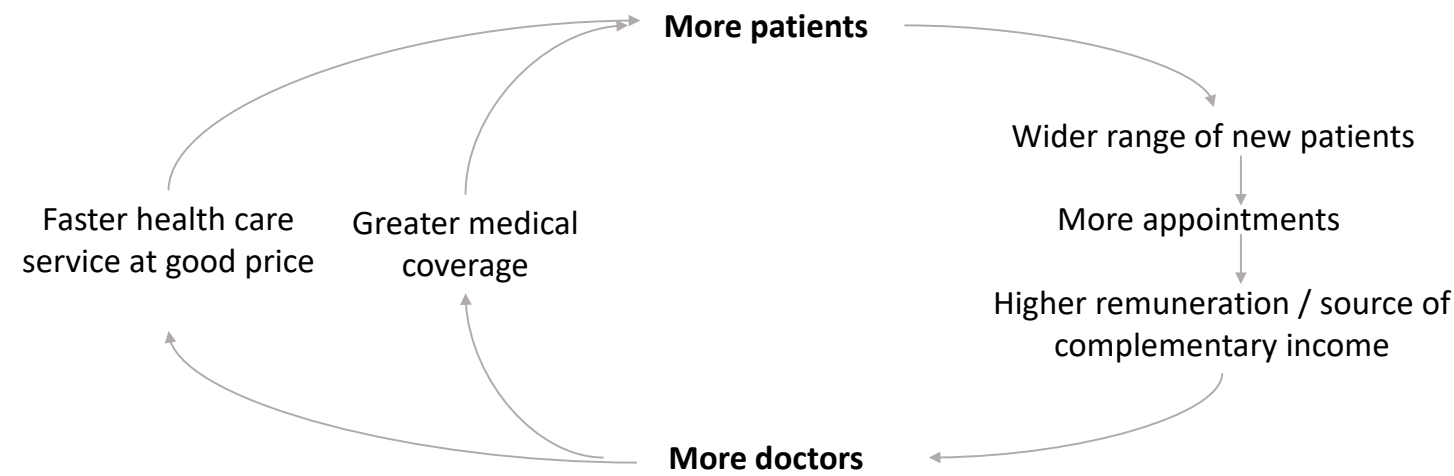

Figure 1. Docpass network effects.

TQ 2.2: Looking at the two sides of the network, how does one side affect the creation of value on the other? Are these impacts positive or negative?

The idea here is to show the network effects, which is when the growth on one side of the network can influence the value on the other. An optional example that the teacher can use to compare for strengthening the understanding of network effects is Uber.

Example: The Uber platform pairs passengers who need to get somewhere with drivers who want to provide a service to gain revenue. What happens with the passengers if Uber starts to operate in a new city with only a few drivers registered? [Passengers will be dissatisfied due to a long waiting time and little convenience and will probably speak poorly of the service to their acquaintances.] On the other hand, what happens to the drivers of this same city if Uber still has few passengers using the service? [These drivers will also be dissatisfied due to a lot of downtime and low revenues, while probably also discouraging other colleagues from registering.] In this context, Uber needs to ensure the growth of both networks, drivers and passengers, in order to create more value for its users and produce a virtuous cycle with an attractive price and a positive reputation. Network effects drive massive user adoption (Eisenmann, Parker, \& Van Alstyne, 2006; Parker et al., 2018).

To succeed in building this virtuous cycle in a twosided market, it could make sense to subsidize one side to drive expansion and gains on the other. In general, the most price-sensitive side is subsidized. Gift coupons are examples of subsidies to increase the network (McAfee \& Brynjolfsson, 2017; Parker et al., 2018).
The same thing occurs with Conexa entering the B2C market. It was necessary to produce positive network effects and mitigate the negative network effects.

In order to grow the user networks and produce positive network effects, Conexa starts from a privileged position since it already had a network of physicians accredited in the $\mathrm{B} 2 \mathrm{~B}$ offer who also started to provide services for the $\mathrm{B} 2 \mathrm{C}$ segment. As already analyzed, the scenario brought by COVID-19 strengthened the network's effects both on the physicians' side, which began to prefer remote health care services and/or looking for new sources of revenue, and on the side of class $\mathrm{C}$ patients looking for remote care at affordable prices. To further drive the patient side, the company practiced a promotional price and simple adherence by implementing credit card payment, used digital marketing tactics, and implemented partnerships with new sales and promotional channels. A challenge with regard to the target audience chosen by Conexa (class $\mathrm{C}$ without health insurance) is that the company had not dealt with this public before and with the abrupt entry into the market, probably more research on the patient's journey will be needed.

In order to mitigate negative network effects, Conexa took steps to predict problems related to rapid growth, implementing a quality curatorship that promoted meeting value expectations for users. In this case, the physicians went through a selective process similar to what an actual hospital would do when screening personnel to be on call. The company also implemented health care protocols based on algorithms recognized in medical associations. Additionally, the appointments are evaluated by Net Promoter Score 
(NPS) with the patient assigning scores to the physicians. Whenever patients are going to choose a doctor for an appointment, they access to the doctor's résumé and his/ her average score from his/her past appointments. One issue that negatively affects the perception of the appointment and that continues without a solution is poor quality internet access by patients.

Question 3: What are the post-COVID-19 challenges in relation to the competitive environment of telemedicine in Brazil?

The objective of this question is to allow the teacher to explore the understanding of the competitive dynamics in a platform ecosystem. The discussion is expected to bring out some of the following aspects:

- Increased demand from consumers and doctors adapted to telemedicine $(+)$.

- Risk of an accelerated growth in the sector without monitoring the quality of service (-).

- Threat of the return of a legal barrier with suspension of regulations (-).

- Threat of other regulatory issues that include access, compatibility, fair pricing, data privacy and security, national control over information resources, tax policy, and labor law (-).

- Entry of new competitors from various sources such as health insurance companies, hospitals, global platforms, and from platforms from other sectors such as technology giants and distance learning platforms (-).

- Entry of new partners with platform solution addons $(+)$.

- Improvement of telemedicine initiatives by incorporating the lessons learned during the pandemic $(+)$.

- Omnichannel strategies to cover the patient's journey by integrating offers through partnerships and/or acquisitions, including with companies from different sectors such as retail and delivery $(+)$.

- Greater variety of health services not restricted to remotely simulating medical appointments that existed in the face-to-face channel (+).

- Development of devices and solutions to make it possible to expand telemedicine into new specialties $(+)$.

The teacher can list the topics raised by the students to fill out the chart. See Slide 4 of the Class Discussion Plan (Appendix).

The platform-based business model changes the very nature of the competition since there is a constant dynamism among the activities of the companies, which makes the strategic advantages rather fleeting. Simple ownership of the infrastructure does not ensure a perennial source of value, but rather getting close to the consumer and the flexibility to create, reconfigure, increase, and capture value in the ecosystem in different ways over time. This flexibility comes from the fact that platforms can take advantage of market opportunities directly or via partnerships that often change the characteristics of the ecosystem. Generally, platforms will try to directly pursue the most attractive opportunities, allowing partners develop the most peripheral ones and share the value produced. Platforms, however, continuously monitor the competitive environment and can quickly decide toward acquisitions or partnerships (Parker et al., 2018).

TQ 3.1: Looking at the challenges you listed in the postCOVID-19 column, who will be the potential new entrants? How could the competitive environment change?

The teacher can use student contributions to fill out the ecosystem vision with new entrants, partners, or offers. See Slides 4 and 5.

TQ 3.2: If you [student] were Conexa's manager, what would you do to take advantage of the opportunities that arise in this ecosystem? What kind of relationships would you establish with the other participants? Where would you try to take actions directly and where would you build partnerships?

The complete ecosystem scheme will tend toward greater complexity in the competition. New platforms and new partners will join the ecosystem, bringing with them other opportunities of interactions and value creation, as well as three distinct forms of competition, whether platform against platform, platform against partner, or partner against partner.

In the competition between platforms, it is likely that if the regulation remains favorable toward telemedicine after the pandemic, there will be an intensification of competition by the entry of other platforms, which may originate in different economic sectors. Those platforms with greater power in the ecosystem as a whole and greater proximity to their users will have a strategic advantage. Conexa is proud to be an independent platform. This could be a strength for opening up a range of partnership possibilities and, therefore, extreme flexibility in the way it operates. On the other hand, other companies could accumulate more data about their patients at different times of the tele-appointment, whether during their journey in other health services (appointments with specialists, hospitals, exams, etc.) or at other times such as when patients are buying, surfing the internet, or using monitoring equipment (e.g., Apple watch). It is necessary to monitor this scenario to understand where 
opportunities are to join efforts with other platforms and partners. Unconventional health care services, new interactions that generate knowledge about the consumer at different times (e.g., interactions among patients), offers in new specialties made possible by devices and software that favor clinical examination, integration of functions and/or modalities that allow the patient an omnichannel experience (without friction between the channels) - all of these are opportunities for direct action or mainly for partnerships.

Platform competition with its partners can be exemplified with Amazon Marketplace. In this situation, Amazon sells its products while giving its partners a platform to sell as well. This is a very delicate movement and though it may have short-term gains for the platform, it may weaken its partners. When Conexa offers tele-appointment with a focus on class $C$ patients without health insurance, in the future it could face competition with partner insurance companies that want to expand their portfolio of offers for this segment via telemedicine. In order to mitigate this risk, Conexa took some steps such as being very transparent with the partners in relation to the movement and creating an independent brand and structures. However, the company may need to think about possible consequences if these measures are not sufficient. Would there be any value to be shared in a possible partnership? To reflect on this issue, it is important to keep in mind that partners can play distinct and multiple roles over time.

The last type of competition refers to partners who compete among each other for the same customers.

As Conexa expands its action in the ecosystem by increasing its partnerships, it needs to be attentive to the values created and shared with its partners, making sure that these partnerships continue to be beneficial for both sides, having as a comparative perspective all the partners of the ecosystem. Value creation partners should be precious.

The teacher could ask for a show of hands from the students who believe that the post-COVID-19 ecosystem will favor opportunities of value that Conexa should take advantage of directly by itself. Then ask students a raise of hands from those who think the ecosystem is offering greater potential for (co)creation of value through partnerships. Ask for the contribution of some students justifying their choice.

The idea is that students realize that favoring platforms toward collaboration and co-creation makes simple competition less relevant. This would be a good time to introduce the term 'coopetition' from the authors Barry Nalebuff, Adam Brandenburger, and Agus Maulana, who explain that "in platform markets, a winning strategy blurs the boundaries among market participants, thereby increasing valuable interactions on the ecosystem" (Parker et al., 2018, p. 227).

Platforms compete very differently from traditional companies and do not fit into classic strategy theories such as the model of Porter's five forces and resource-based vision (RBV). Competition on the platforms involves other aspects such as limiting access to participation in an ecosystem; seeking innovations and (co)creation of value; leveraging data usage and monetization; market reconfigurations in terms of mergers, acquisitions, and partnerships; enveloping the platform by including better functionalities than other competitors; and improving the design and the user experience.

At this time, the teacher may choose to get into the details of one or more of these aspects.

\section{Closing discussion}

The closing minutes could be used to reflect on the dilemma presented by the protagonists. The case ends with them concerned about a possible return of legislation once again prohibiting tele-appointments. In this case, the teacher could recap the lessons learned from the schemes proposed on the chart (platform concept, network effects, and competitive dynamics in platform markets) and open the discussion about one of the characteristics of entrepreneurs - risk taking. If $\mathrm{B} 2 \mathrm{C}$ platforms could no longer operate, what would the partners do with Docpass and the lessons learned? Could the journey of creating the company serve to leverage previous and/or new business? What partnerships could be promising? The answer to these questions highlights the importance of the diagnosis made during the discussion of the case about how platforms operate in an environment of networks and coopetition. With the experience of Docpass, Conexa becomes even more prepared to take action in new realities. Companies operate in contexts of constant variations of the external environment, generating high uncertainty, so taking risks is a recurrent characteristic in the decisions of entrepreneurs. 


\section{REFERENCES}

Eisenmann, T., Parker, G., \& Van Alstyne M. W. (2006). Strategies for two-sided markets. Harvard Business Review, 84(10), 92. Retrieved from https://hbr.org/2006/10/strategies-for-two-sided-markets

Hagiu (2014). Strategic decisions for multisided platforms. MIT Sloan Management Review, 55, 71-80. Retrieved from https://www.hbs.edu/faculty/Pages/item.aspx?num=46062

McAfee, A., \& Brynjolfsson, E. (2017) Machine, platform, crowd: Harnessing our digital future. New York: Norton \& Company.

\section{Authorship}

\section{Catia Silva da Costa Moreira*}

Universidade Federal Fluminense, Faculdade de Administração e Ciências Contábeis, Departamento de Empreendedorismo

Rua Mário Santos Braga, s/n, Prédio 1, $7^{\circ}$ Andar, Centro, 24220900, Niterói, RJ, Brazil

E-mail address: catia.moreira@coppead.ufrj.br

(D) https://orcid.org/0000-0003-3969-6693

\section{Flavia D’Albergaria Freitas}

Universidade Federal do Rio de Janeiro, Instituto COPPEAD de Administraçáo

Rua Pascoal Lemme, no 355, Cidade Universitária, 21941-918, Rio

de Janeiro, RJ, Brazil

E-mail address: flaviadaf@gmail.com

(D) https://orcid.org/0000-0003-4870-2864

\section{Carolina Brandão}

Pontifícia Universidade Católica do Rio de Janeiro

Rua Marquês de São Vicente, no 225, Gávea, 22541-041, Rio de Janeiro, RJ, Brazil

E-mail address: carolina.brandao@coppead.ufrj.br

(D) https://orcid.org/0000-0003-0294-8893

\section{Cláudia Affonso Silva Araujo}

Universidade Federal do Rio de Janeiro, Instituto COPPEAD de Administração

Rua Pascoal Lemme, no 355, Cidade Universitária, 21941-918, Rio de Janeiro, RJ, Brasil

Fundação Getulio Vargas, Escola de Administração de Empresas de Sáo Paulo

Av. 9 de julho, no 2029, Bela Vista, 01313-902, São Paulo, SP, Brazil

E-mail address: claraujo@coppead.ufrj.br

(D) https://orcid.org/0000-0003-0290-4807

* Corresponding Author

\section{Copyrights}

RAC owns the copyright to this content.

\section{Conflict of Interests}

The authors have stated that there is no conflict of interest.
Parker, G., Van Alstyne, M. W., \& Choudary, S. (2018). Plataforma a reevolução da estratégia: $O$ que é a plataforma de negócios, como surgiu e como transforma a economia em alta velocidade. Rio de Janeiro: Alta books.

Shapiro \& Varian (2003). A economia da informação. Rio de Janeiro: Elsevier.

Tiwana (2013). Platform ecosystems: Aligning architecture, governance, and strategy. Burlington, MA: Morgan Kaufmann.

\section{Authors' Contributions}

$1^{\text {st }}$ author: conceptualization (lead); data curation (lead); formal analysis (lead); investigation (lead); methodology (lead); writing-original draft (equal).

$2^{\text {nd }}$ author: conceptualization (support); data curation (support); formal analysis (equal); methodology (equal); writing-original draft (equal).

$3^{\text {rd }}$ author: conceptualization (support); Investigation (support); data curation (support); writing-original draft (support).

$4^{\text {th }}$ author: conceptualization (support); investigation (support); methodology (support); writing-original draft (support); writing-review \& editing (lead).

\section{Funding}

The authors reported that there is no financial support for the research in this article.

\section{Plagiarism Check}

The RAC maintains the practice of submitting all documents approved for publication to the plagiarism check, using specific tools, e.g.: iThenticate.

\section{Peer Review Method}

This content was evaluated using the double-blind peer review process. The disclosure of the reviewers' information on the first page, as well as the Peer Review Report, is made only after concluding the evaluation process, and with the voluntary consent of the respective reviewers and authors.

\section{Data Availability}

RAC encourages data sharing but, in compliance with ethical principles, it does not demand the disclosure of any means of identifying research subjects, preserving the privacy of research subjects. The practice of open data is to enable the reproducibility of results, and to ensure the unrestricted transparency of the results of the published research, without requiring the identity of research subjects. 


\section{APPENDIX A}

\section{Pre-COVID}

\section{1}

Scenario of Telemedicine:

- Technology available (+)

- Cultural Barrier (-)

- Low technological skills by users (-)

- Younger users were already familiar with technology $(+)$

- An attempt at regulation in 2019 failed due to resistance and protests from medical associations (-)

\section{Conexa Offers}

- Software as a Service - SaaS

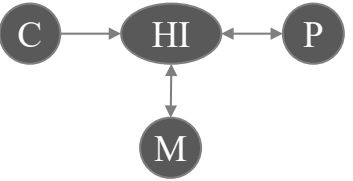

- Tele-appointments (B2B)

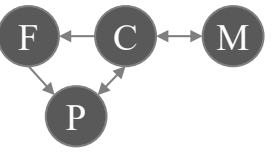

\section{During COVID}

\section{2}

\section{Scenario of Telemedicine:}

- Remote care offered advantages (+)

- Patients with other diseases: not getting exposed to risks $(+)$

- Health services above their capacity $(+)$

- Option for physicians to generate revenue $(+)$

- New regulation $(+)$

- Health insurance companies paying for tele-appointments $(+)$

- Increased use of platforms in general $(+)$

- Some specialties are limited since physical exams are needed $(-)$

- Players with different levels of maturity. (+/-)

\section{Conexa Offers \\ - Docpass}

\section{P}

Quick service Convenience Quality

Search for patients

Promotional price

Means of payment

Digital marketing

Partnerships

\section{C} M

New patients Fair remuneration Experience made easy Convenience Quality infrastructure Doctors already accredited

\section{Network Effects}

+ New doctors

NPS Curatorship of doctors Appointment protocols

\section{Post-COVID}

\section{Scenario of Telemedicine:}

- Increased demand from consumers and doctors possibly adapted to telemedicine $(+)$

- Risk of the accelerated growth affecting quality of service (-)

- Risk of the return of a legal barrier with suspension of regulations (-)

- Threat of other regulatory issues (-)

- Entry of new competitors from various sources (-)

- Entry of new partners with platform solution add-ons $(+)$

- Improvement of telemedicine initiatives $(+)$

- Omnichannel strategies (+)

- Greater variety of health services $(+)$

- Development of devices and solutions to make it possible to expand telemedicine into new specialties $(+)$

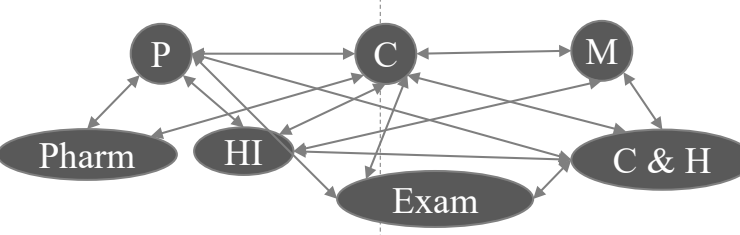

\section{“Coopetition" Platform}

- Access limitation

- Stimulating innovation and capturing value

- Leverage of data value
- Redefinition of mergers \& acquisitions

- Enveloping the Platform

- Design Enhancement

- Sustained Advantage

Figure A1. Class discussion plan (scheme proposed for the table).

Source: Authors.

RAC is a member of, and subscribes to the principles of the Committee on Publication Ethics (COPE) for scholarly publication 